\title{
PET Monitoring of Therapy Response in Head and Neck Squamous Cell Carcinoma
}

\author{
Heiko Schöder ${ }^{1}$, Matthew Fury ${ }^{2}$, Nancy Lee ${ }^{3}$, and Dennis Kraus ${ }^{4}$ \\ ${ }^{1}$ Department of Radiology, Nuclear Medicine Service, Memorial Sloan-Kettering Cancer Center, New York, New York; ${ }^{2}$ Department \\ of Medicine, Head and Neck Oncology Service, Memorial Sloan-Kettering Cancer Center, New York, New York; ${ }^{3}$ Department of \\ Radiation Oncology, Memorial Sloan-Kettering Cancer Center, New York, New York; and ${ }^{4}$ Department of Surgery, Head and Neck \\ Surgery Service, Memorial Sloan-Kettering Cancer Center, New York, New York
}

\begin{abstract}
In the Western world, more than $90 \%$ of head and neck cancers are head and neck squamous cell carcinomas (HNSCCs). The most appropriate treatment approach for HNSCC varies with the disease stage and disease site in the head and neck. Concurrent chemoradiotherapy has become a widely used means for the definitive treatment of locoregionally advanced HNSCC. Although this multimodality treatment provides higher response rates than radiotherapy alone, the detection of residual viable tumor after the end of therapy remains an important issue and is one of the major applications of ${ }^{18} \mathrm{~F}-\mathrm{FDG}$ PET. Studies have
\end{abstract} shown that negative ${ }^{18} \mathrm{~F}-\mathrm{FDG}$ PET or PET/CT results after concurrent chemoradiotherapy have a high negative predictive value (>95\%), whereas the positive predictive value is only about $50 \%$. However, when applied properly, FDG PET/CT can exclude residual disease in most patients, particularly patients with residual enlarged lymph nodes who would otherwise undergo neck dissection. In contrast to other malignancies, data are limited on the utility of ${ }^{18} \mathrm{~F}$-FDG PET for monitoring the response to induction chemotherapy in HNSCC or for assessing treatment response early during the course of definitive chemoradiotherapy. The proliferation marker ${ }^{18} \mathrm{~F}-3^{\prime}$-deoxy-3'fluorothymidine is currently under study for this purpose. Beyond standard chemotherapy, newer treatment regimens in HNSCC take advantage of our improved understanding of tumor biology. Two molecules important in the progression of HNSCC are the epidermal growth factor receptor and the vascular endothelial growth factor (VEGF) and its receptor VEGF-R. Drugs attacking these molecules are now under study for HNSCC. PET probes have been developed for imaging the presence of these molecules in HNSCC and their inhibition by specific drug interaction; the relevance of these probes for response assessment in HNSCC will be discussed. Hypoxia is a common phenomenon in HNSCC and renders cancers resistant to chemoand radiotherapy. Imaging and quantification of hypoxia with PET probes is under study and may become a prerequisite for overcoming chemo- and radioresistance using radiosensitizing drugs or hypoxia-directed irradiation techniques and for monitoring the response to these techniques in selected groups of patients. Although ${ }^{18} \mathrm{~F}$-FDG PET/CT will remain the major clinical tool for monitoring treatment in HNSCC, other PET probes may have a role in identifying patients who are likely to benefit from treatment strate-

Received Jan. 27, 2009; revision accepted Mar. 25, 2009.

For correspondence or reprints contact: Heiko Schöder, Departments of Radiology and Nuclear Medicine, Memorial Sloan-Kettering Cancer Center, 1275 York Ave., Box 77, New York, NY 10065.

E-mail: schoderh@mskcc.org

COPYRIGHT $\odot 2009$ by the Society of Nuclear Medicine, Inc. gies that include biologic agents such as epidermal growth factor receptor inhibitors or VEGF inhibitors.

Key Words: oncology; PET; PET/CT; head and neck cancer; treatment response

J Nucl Med 2009; 50:74S-88S

DOI: 10.2967/jnumed.108.057208

$\mathbf{H}_{\mathrm{e}}$ ead and neck cancer is the sixth most common cancer worldwide. In the Western world, more than $90 \%$ of these malignancies are head and neck squamous cell carcinomas (HNSCCs). Approximately 47,000 new cases of HNSCC were diagnosed in the United States in 2008 (1). The worst prognosis is seen in patients with unresectable advanced disease, with a 5-y survival rate of less than $10 \%$. Selection of the most appropriate treatment approach varies with disease stage and site in the head and neck.

\section{CURRENT CLINICAL PRACTICE}

Patients with early-stage disease are generally treated with unimodality therapy consisting of either surgery or radiotherapy, and nearly $80 \%$ are cured. Postoperative radiotherapy is recommended when the risk for locoregional recurrence in the head and neck exceeds $20 \%$. For patients whose disease is not controlled with definitive radiotherapy, salvage surgery is recommended. In patients who undergo surgery for more advanced lesions, postoperative adjuvant radiotherapy is generally part of the treatment plan. Improvements in locoregional control rates, progression-free survival (2), and overall survival (3) can be achieved at the expense of an increased rate of acute treatment-related adverse events. The pooled analysis of these 2 randomized trials suggested that concurrent chemoradiotherapy should be offered when surgical margins are positive for tumor or when lymph nodes show extracapsular extension (4).

Patients with locoregionally advanced disease that is surgically unresectable, and patients in whom definitive treatment is administered with an attempt at organ preservation (e.g., oropharyngeal and laryngeal carcinomas), undergo treatment with concurrent chemoradiotherapy $(5,6)$. Cis- 
platin is the drug with the most randomized clinical trial data to support its use as a drug enhancing the effects of radiotherapy in this setting. The larynx-preservation paradigm is supported by the results of a study that randomized 547 patients with stage 3 or 4 supraglottic and glottic laryngeal cancer into 3 treatment arms: concurrent chemoradiotherapy, induction chemotherapy consisting of cisplatin and 5fluorouracil (5-FU) followed by radiotherapy, or radiotherapy alone. After a median follow-up of $3.5 \mathrm{y}$, the rates of locoregional control were $78 \%, 61 \%$, and $56 \%$, respectively. The fraction of patients who maintained an intact larynx at $2 \mathrm{y}$ (and thus the ability to speak and swallow after the end of therapy) was also better with the concurrent regimen (88\%, $75 \%$, and $70 \%$, respectively) (5). Overall survival rates were similar in all 3 groups. The utility of concurrent high-dose cisplatin for other subsites was established in a randomized study of 295 patients with unresectable head and neck cancer (7). Patients were randomized to radiotherapy alone, radiotherapy plus concurrent high-dose cisplatin, or radiotherapy (split course) plus cisplatin and 5-FU. With a median followup of $41 \mathrm{mo}, 3$-y overall survival results were $23 \%, 37 \%$, and $27 \%$, respectively. Improved locoregional control rates were also reported for concurrent chemoradiotherapy with a drug combination of carboplatin and 5-FU (6). In 226 patients with stage 3 or 4 oropharynx cancer, the 5-y rates of locoregional control were $48 \%$ for concurrent therapy, compared with $24 \%$ for radiotherapy alone. Concurrent chemoradiotherapy is therefore now widely applied as the definitive treatment of choice for locoregionally advanced HNSCC. If residual disease is detected after the end of therapy or during follow-up, salvage surgery (e.g., laryngectomy) may be offered.

The management of the neck when using an organpreservation approach has remained somewhat controversial. Complete response rates in irradiated cervical lymph nodes vary between $59 \%$ and $83 \%$ and to some degree are related to nodal size, dose of radiotherapy, and time point when response is determined: complete response rates are almost $100 \%$ in N1 disease, higher in N2 than in N3 disease, and better when the largest metastatic node is smaller than $3 \mathrm{~cm}$ (8). In N2 or N3 disease, residual cancer in neck nodes has been reported in 16\%-39\% of patients achieving a clinical complete response (no overt residual neck mass) (8-11). Early studies (12) demonstrated better outcomes when radiotherapy was followed by neck dissection, leading to the practice of "planned neck dissection" for all patients with N2 or N3 disease on presentation (regardless of the response to treatment) and for patients with N1 disease and persistent palpable lymph nodes after irradiation (13-15). More recently, however, the improved locoregional control rates with concurrent chemoradiotherapy have prompted a debate on whether planned neck dissection is still appropriate or necessary in all patients with initial N2 or N3 disease. Proponents of this approach argue that because clinical examination and structural imaging cannot reliably identify residual viable tumor, neck dissection is the only means to eradicate all residual disease in the neck (9). In contrast, opponents suggest that neck dissection be performed only in high-risk patients, whereas close clinical follow-up and observation may be appropriate in most cases. Several recent studies have tried to define the utility of ${ }^{18} \mathrm{~F}$-FDG PET in this patient population. These will be discussed later in this article.

Patients with recurrent or metastatic disease have a median survival of approximately 6-9 mo. Therapeutic options include chemotherapy alone, irradiation or reirradiation with or without chemotherapy, salvage surgery, or best supportive care for patients with a low performance status. Reirradiation with concurrent chemotherapy is feasible for recurrent unresectable HNSCC but is associated with considerable acute and long-term toxicity (16-19).

In summary, the suboptimal disease control rates and survival figures in HNSCC emphasize the need for early disease detection in the primary and recurrent settings and a need for better imaging tools for staging and response assessment. There is also a clear need to investigate new therapeutic regimens and drugs, such as biologic and molecular agents.

\section{NEWER BIOLOGIC THERAPIES}

\section{Antiangiogenesis Therapies}

The sprouting of new vessels (angiogenesis) is essential for tumor growth and metastasis (20). Tumor cell proliferation alone, in the absence of angiogenesis, may give rise to dormant, microscopic tumors of about $1 \mathrm{~mm}^{3}$ or less, but these in situ cancers are harmless to the host $(21,22)$. The term angiogenic switch has been used to describe the step when tumors acquire the ability to recruit their own blood supply to support growth beyond microscopic size (23). Preclinical research from the past 20 y suggests that complete pharmacologic blockade of tumor angiogenesis will leave only residual microscopic lesions, which may be clinically harmless and manageable as a chronic condition (23). Of note, the newly formed tumor vessels are structurally abnormal ("leaky") and dysfunctional, delivering less blood and oxygen and fewer nutrients than normal blood vessels of similar caliber. Their leakiness (hyperpermeability) also causes increased interstitial pressure. Ultimately, these properties limit the build-up of sufficient drug concentrations within the tumor (24) and promote the development of hypoxic tumor subregions. Hypoxia in turn is one of the strongest promoters of angiogenesis (25-31).

Antiangiogenic therapies are particularly directed against these newly formed tumor vessels and may thus reduce or eliminate the excess supply of nutrients that are needed for tumor growth (32). Paradoxically, these drugs may also improve drug distribution within the tumor and reduce levels of intratumoral hypoxia because they eliminate the dysfunctional, leaky tumor vessels and thereby reduce intratumoral interstitial pressure (24). Angiogenesis is tightly regulated by several molecules (33); the best known and studied of these is the vascular endothelial growth factor (VEGF). Increased 
levels of VEGF are found in many HNSCCs and in patient serum $(34,35)$. High VEGF expression is a marker of poor prognosis, correlating with higher clinical stage (36), high rates of locoregional recurrence, and lower disease-free and overall survival $(37,38)$. Accordingly, there is great interest in exploiting antiangiogenic therapies for the treatment of HNSCC.

Bevacizumab, a recombinant humanized, monoclonal IgG antibody against VEGF, has been studied in HNSCC in combination with chemotherapy (33). Trials testing the combination of bevacizumab with cisplatin and radiotherapy are ongoing (39). VEGF receptor tyrosine kinase inhibitors have been studied in smaller phase I trials (40), and combination therapies of bevacizumab with tyrosine kinase inhibitors are being developed (41). Experimentally, synergistic (supraadditive) effects have been observed for the combination of bevacizumab with the epidermal growth factor receptor (EGFR) tyrosine kinase inhibitor erlotinib, as well as for the EGFR kinase inhibitor gefitinib and specific VEGF receptor tyrosine kinase inhibitors in conjunction with irradiation $(42,43)$. The rationale for combining biologic agents with radiotherapy is based on evidence from experimental studies. Contrary to the concern that antiangiogenic therapy may cause or promote tumor hypoxia and hence radioresistance, it is indeed the newly formed tumor vessels that contribute to radioresistance. In tumor xenografts, external irradiation induces a 2- to 3-fold increase in VEGF expression and secretion that lasts for up to $14 \mathrm{~d}$ (44). This mechanism may contribute to protecting tumor blood vessels from radiation-mediated cytotoxicity and thus in fact promotes radioresistance (the tumor protecting itself). This radiation-induced angiogenesis can be suppressed by bevacizumab and erlotinib (43).

\section{Therapies Targeting the EGFR}

The EGFR is a member of the ErbB family of tyrosine kinase receptors. It is overexpressed or activated in most HNSCCs relative to normal tissue (45), and high expression is associated with poor disease control (46-49). EGFR copy number as determined by quantitative reverse-transcriptase polymerase chain reaction is inversely related to patient outcome: in a study of 134 patients with primary HNSCC, the 5-y survival in individuals with an increased EGFR copy number was only $9 \%$, compared with $71 \%$ in individuals with a normal copy number (50). Although these data suggest that HNSCC is an ideal malignancy for treatment with EGFR inhibitors, the selection of appropriate patients for therapy with these agents remains challenging. In studies of antiEGFR agents in patients with advanced HNSCC, the objective response rates have been approximately $10 \%$, with the percentage depending on the specific agent (51).

Cetuximab, a chimeric IgG1 antibody against the extracellular domain of EGFR, is the most widely studied agent. Cetuximab receptor binding competes with the binding of the natural EGFR ligands and blocks the activation of the receptor tyrosine kinase (52). Cetuximab has been studied in recurrent HNSCC in combination with cisplatin (53) or in combination with platinum plus 5-FU (54) as a first-line treatment and also as a secondary treatment option in cases of platinum-refractory disease (55-57). In these trials including a total of almost 400 patients, the response rates based on CT or MRI assessment of target lesions were in the range of $10 \%-26 \%$, although the disease control rates (a parameter that includes all patients with complete response, partial response, or stable disease) were as high as $46 \%-53 \%(55,57)$. In the largest trial to date (EXTREME trial), 442 patients with untreated metastatic or recurrent HNSCC were randomized to treatment with 5-FU plus either carboplatin or cisplatin, or the same chemotherapy regimen plus cetuximab. The addition of cetuximab increased the response rate from $20 \%$ to $36 \%(P<0.001)$ and improved the median overall survival slightly but significantly from 7.4 to $10.1 \mathrm{mo}(58)$.

Cetuximab also enhances the efficacy of radiation therapy. In a large, randomized study of 420 patients with locoregionally advanced HNSCC (59), the addition of cetuximab to radiotherapy improved locoregional tumor control and overall survival without increasing mucositis and dysphagia, when compared with radiotherapy alone. The corresponding median progression-free survival was 24 versus $15 \mathrm{mo}$, and the median overall survival was 49 versus 29 mo. Although this study did establish concurrent radiotherapy plus cetuximab as a viable treatment option in locoregionally advanced HNSCC, the study has also been criticized because the control group was treated with radiotherapy alone whereas the present standard regimen would be concurrent chemoradiotherapy. This issue is being addressed in ongoing clinical trials. One study is randomizing patients to induction chemotherapy followed by cisplatin plus radiotherapy versus induction chemotherapy followed by cetuximab with radiotherapy (60). Another randomized study is comparing standard concurrent chemoradiotherapy versus concurrent chemoradiotherapy plus cetuximab (61).

Other EGFR-inhibiting drugs include the small-molecule tyrosine kinase inhibitors gefitinib and erlotinib, which have been tested as single agents $(62,63)$ or in combination with cisplatin (64). When used in combination with cisplatin, erlotinib seemed to have an additive effect, leading to an objective partial or complete response in $21 \%$ of patients and disease stabilization in $49 \%$. However, the median progressionfree survival was only 3 mo.

In summary, there is a sound scientific rationale for applying biologic agents against EGFR and VEGF in patients with locoregionally advanced or metastatic HNSCC. Unfortunately, major clinical responses are relatively rare. The selection of appropriate patients for therapy with these new and expensive drugs remains challenging.

\section{RESPONSE ASSESSMENT WITH ${ }^{18}$ F-FDG PET}

${ }^{18}$ F-FDG PET After Chemo- or Radiotherapy

Structural imaging with contrast-enhanced CT or MRI and functional imaging with ${ }^{18}$ F-FDG PET are now con- 
sidered standard for assessing the response to therapy in HNSCC. In this section, we shall focus on studies in which ${ }^{18}$ F-FDG PET was used in patients treated with curative intent. Response rates at the site of primary disease are generally high with concurrent chemoradiotherapy. Therefore, the main focus of posttherapy PET is the detection of residual disease in neck lymph nodes. Tables 1 and 2, a summary of published data, show that most studies on posttherapy ${ }^{18} \mathrm{~F}$-FDG PET in HNSCC included heterogeneous patient populations and that all the data come from retrospective analyses:

- Patient selection criteria varied: Some studies included consecutive patients after chemo- or radiotherapy regardless of clinical or structural imaging findings. Some studies enrolled only patients with residual structural abnormality on clinical examination or CT/MRI. Some studies excluded patients with suspected or proven residual abnormality at the primary disease site and specifically addressed the role of PET for detecting residual cancer in neck lymph nodes.

- Disease sites varied: Most studies focused on the utility of PET for response assessment after concurrent chemoradiotherapy (which is applied mostly for malignancies in the oropharynx and larynx), but some studies also included a large fraction of patients with other disease sites (nasopharynx, paranasal sinuses, skin). This difference is critical because tumor biology, clinical behavior, expected response rates, and the potential for false-positive findings differ between these latter cancers and tumors of the oropharynx and larynx.

- Treatment strategies varied somewhat: One institution (65) reported on the utility of PET after induction chemotherapy (which is currently not considered a standard approach) and after subsequent definitive concurrent chemoradiotherapy, whereas all other studies focused on the outcome after definitive therapy.

- Treatment protocols varied somewhat: Most but not all patients were treated with concurrent chemoradiotherapy. It is clear that greater posttreatment inflammation is expected after concurrent therapy than after irradiation alone. Chemotherapy acts as a radiation sensitizer in the irradiated tumor but also in the surrounding normal tissue that is included in the radiation field. Studies also differ in radiotherapy schedules, doses, and techniques. Only one study specifically addressed the role of PET after intensity-modulated radiotherapy (66).

- Use of PET/CT versus only PET varied: Only a few recent studies specifically studied the role of combined PET/CT in this setting (67-70). In some other studies, a fraction of patients was imaged with PET/CT, but other patients were imaged with PET only. Earlier studies generally assessed the utility of PET only. This difference between studies is important because combined PET/CT reduces the number of equivocal findings and improves study accuracy $(71,72)$.
- Appropriate time for PET in response assessment varied: Perhaps most important, the time between the end of therapy and the PET scan varied considerably, ranging from $4 \mathrm{wk}$ to almost $1 \mathrm{y}$. In a study of 26 patients, Goerres et al. (73) observed a sensitivity and specificity of $91 \%$ and $93 \%$, respectively, for PET scans performed as early as $6 \mathrm{wk}$ after chemoradiotherapy. We and others have not been able to reproduce these data $(74,75)$ and instead suggest that posttherapy PET after chemoradiotherapy should not be performed before 10-12 wk after the end of treatment. By that time, most of the posttreatment inflammatory changes will have subsided, reducing the number of potentially false-positive interpretations. In general, the rate of false-positive cases declines with the interval between end of therapy and PET (76). Therefore, it is not surprising that studies that include a large fraction of patients in whom PET was performed as late as 6 mo after the end of therapy will have a lower false-positive rate. Some studies also demonstrated a higher false-negative rate when PET was done less than 4-8 wk after the end of therapy $(68,77)$. It is conceivable that small-volume residual disease at this early time escapes detection on PET. Of note, most irradiated cells do not die instantaneously but instead can still undergo several cycles of cell division (only cells irradiated in the mid to late S-phase show instantaneous cell cycle blockade). Their subsequent fate varies: some cells may remain dormant for a protracted time and die eventually, but some cells may recover and start dividing again $(78,79)$. Indeed, experimental studies on irradiated cell cultures show a rapid decline in ${ }^{18} \mathrm{~F}$-FDG uptake, but the tracer uptake is not instantaneously abolished. Dormant cancer cells maintain their capability for glucose uptake and retention as long as their cell membrane is intact and basic metabolic processes continue. Some of these cells eventually die, whereas other cells may recover their full metabolic and proliferative potential. With increasing volume, the residual viable tumor cell nests may eventually become detectable on ${ }^{18}$ F-FDG PET.

We would like to highlight some of the studies listed in Tables 1 and 2 to demonstrate the utility of ${ }^{18}$ F-FDG PET in HNSCC after irradiation and chemoradiotherapy. Data are based on the number of patients or on the number of heminecks in which disease was initially diagnosed. The first study included 53 patients (70 heminecks) who were imaged with PET or PET/CT (75). The median interval between end of therapy and PET was $15 \mathrm{wk}$. Twenty-eight of the 70 heminecks harbored residual enlarged lymph nodes. Using neck dissection or clinical follow-up as the standard of reference, ${ }^{18} \mathrm{~F}$-FDG PET showed a sensitivity of $100 \%$ and a specificity of $94 \%$, with a positive predictive value (PPV) of $43 \%$ and a negative predictive value (NPV) of $100 \%$. The second study evaluated 39 patients who achieved a complete 


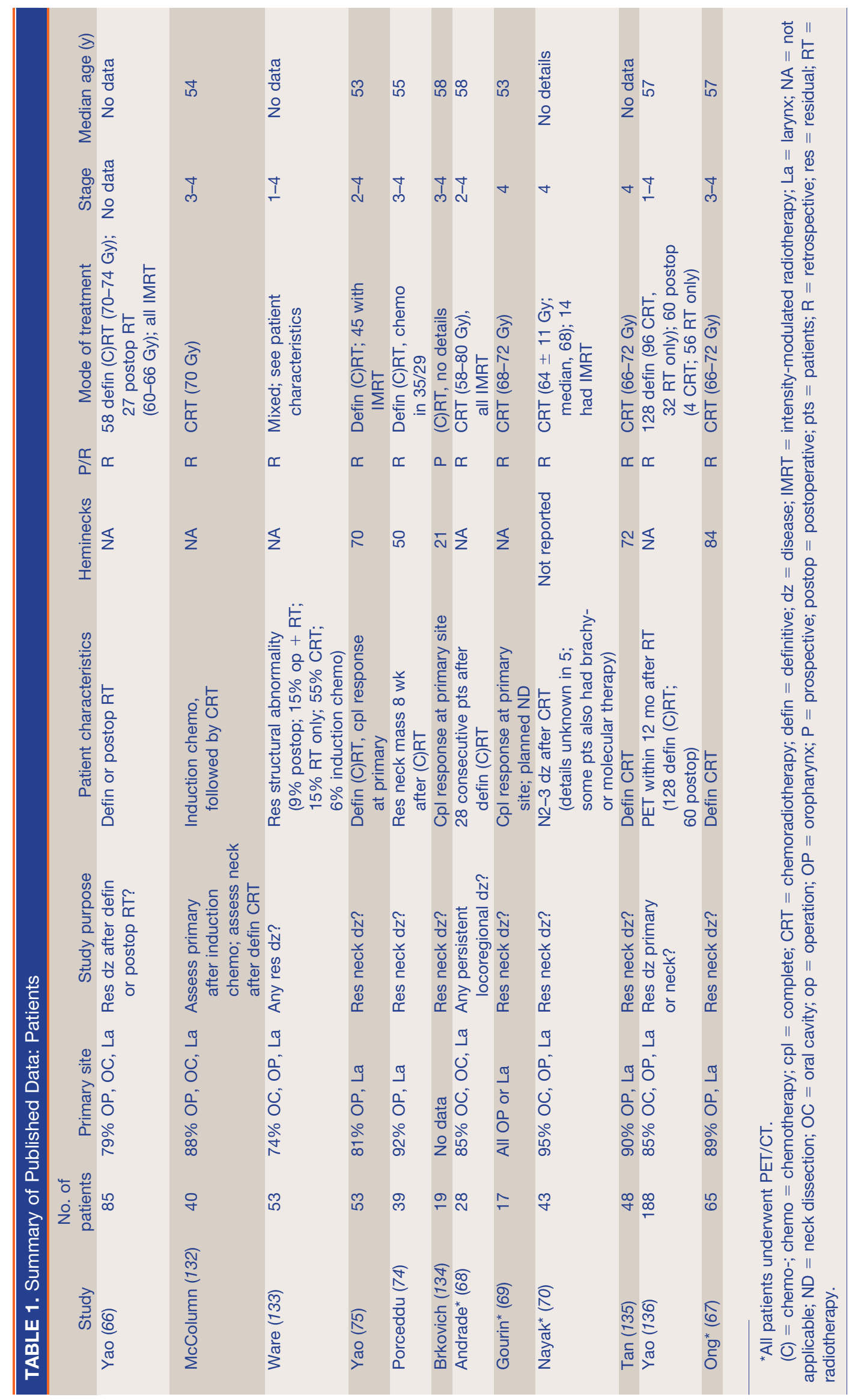


II

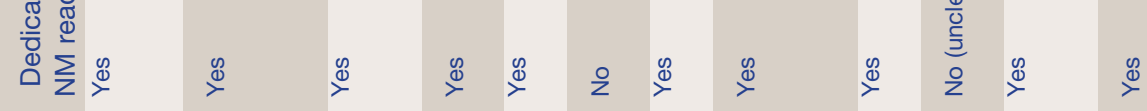

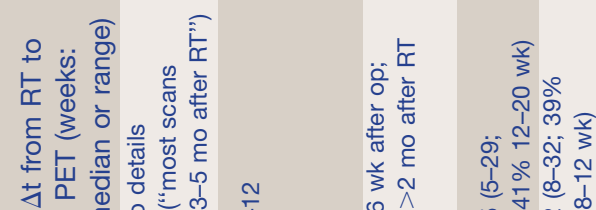

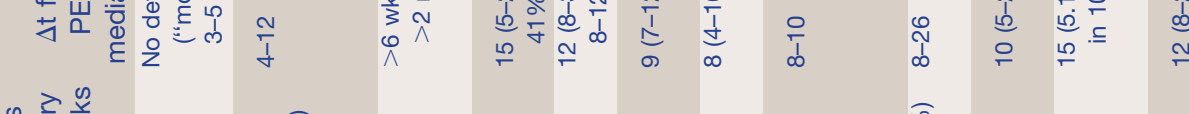

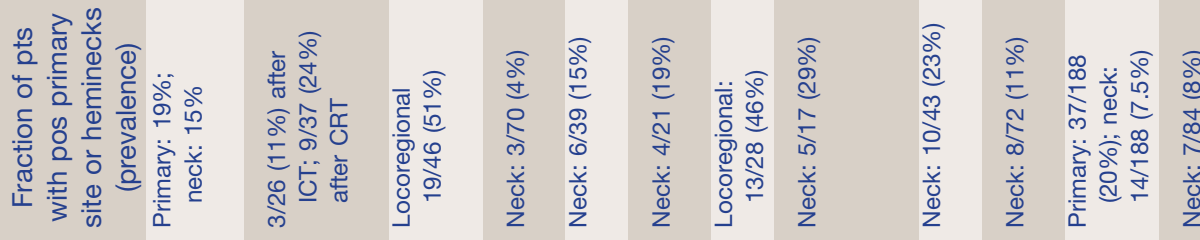

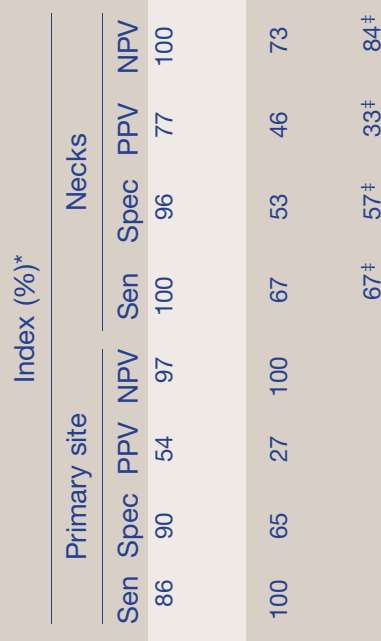

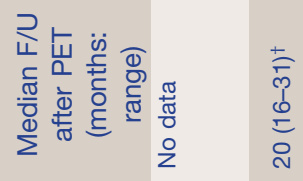

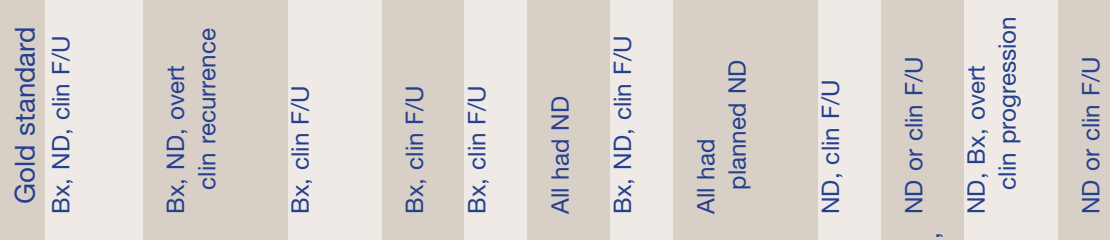

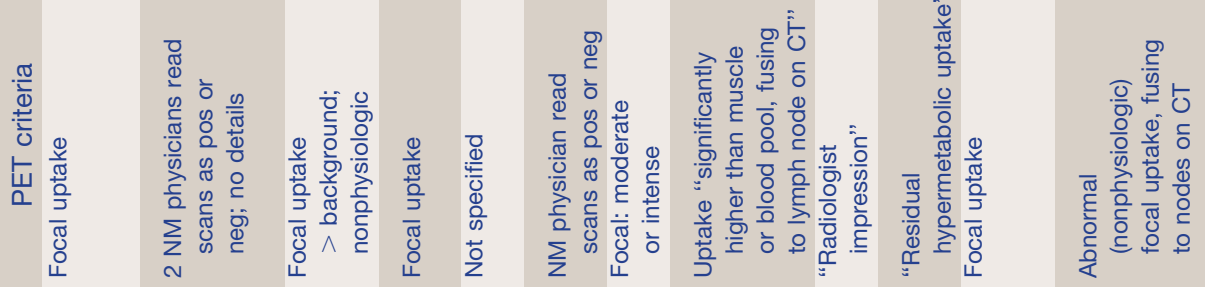

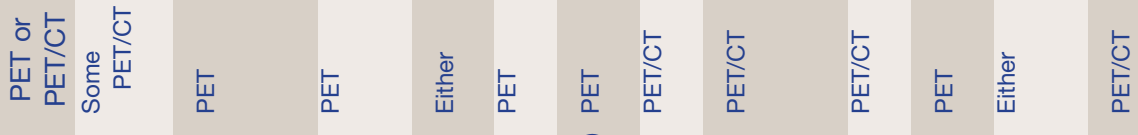

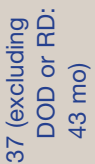

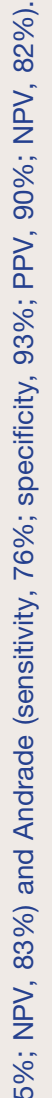

(n)

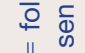

강

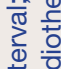

$\stackrel{2}{\simeq}$

จ 요

象

$\ddot{0}$

일

莒

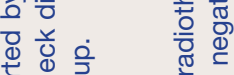

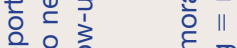

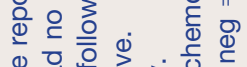

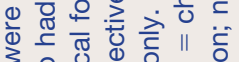

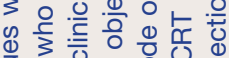

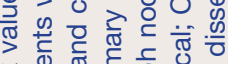

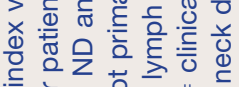

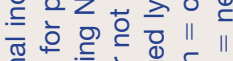

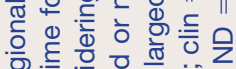
क्षे

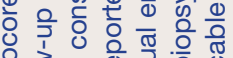

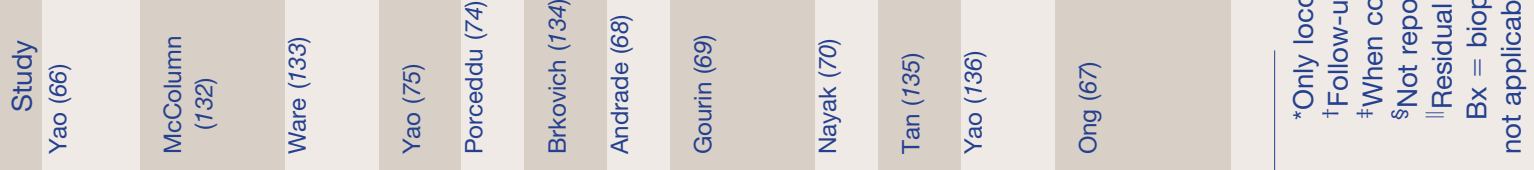


response to concurrent chemoradiotherapy at the primary site but had a residual neck mass (74). ${ }^{18} \mathrm{~F}$-FDG PET, performed at a median of $12 \mathrm{wk}$ after the end of therapy, had a sensitivity of $83 \%$ and a specificity of $93 \%$; the NPV was $97 \%$. Residual nodal metastasis was eventually proven in 6 of the 39 individuals; hence the PPV of structural imaging was only 15\%. Finally, Ong et al. (67) studied 65 patients (84 heminecks) after concurrent chemoradiotherapy. ${ }^{18} \mathrm{~F}-\mathrm{FDG}$ PET/ CT was performed on all patients at least $8 \mathrm{wk}$ after the end of therapy. The standard of reference consisted of histopathology of neck dissection specimens or clinical and imaging follow-up. In this study, the sensitivity and specificity were $71 \%$ and $89 \%$, respectively, with a PPV of $38 \%$ and an NPV of 97\%. All false-positive lymph nodes in neck dissection specimens showed either inflammation or granulomatous disease, which are known causes of increased ${ }^{18}$ F-FDG uptake in lymph nodes. Nevertheless, the fraction of falsepositive studies could be reduced from $27 \%$ to $10 \%$ when the neck was assessed by combined PET/CT rather than by structural imaging alone, while maintaining a high NPV of $97 \%$. The true value of posttherapy ${ }^{18} \mathrm{~F}$-FDG PET in patients treated with current radio- or chemoradiotherapy is the high NPV. Many patients who might otherwise proceed to biopsy or planned neck dissection can in fact be observed with clinical follow-up and periodic imaging studies. Although the PPV of PET after chemoradiotherapy is relatively low, most scans will in fact have negative findings when interpreted properly. However, true prolonged, intense ${ }^{18} \mathrm{~F}-\mathrm{FDG}$ uptake after definitive therapy indicates a poor treatment outcome or treatment-related complications: In an interesting study on patients with laryngeal cancer treated with intensity-modulated radiotherapy, Dornfeld et al. (80) showed an inverse relationship between the intensity of (persistent) ${ }^{18}$ F-FDG uptake at 12 mo after treatment and quality of life, the ability to speak, and the ability to swallow solid foods. In other words, persistent ${ }^{18} \mathrm{~F}$-FDG uptake indicates either persistent disease or persistent treatmentinduced structural and functional damage to the larynx.

\section{Suggested PET Interpretation Criteria}

Combined PET/CT, rather than PET only, should be used because it is more accurate and avoids equivocal interpretations, can distinguish between ${ }^{18} \mathrm{~F}$-FDG uptake in normal structures versus lymph nodes, can guide biopsies, and can potentially guide planning of the target for adjuvant radiotherapy $(71,72,81,82) .{ }^{18} \mathrm{~F}$-FDG uptake in the treated neck should decline within weeks, allowing an accurate reading to be rendered at approximately 10-12 wk after the end of chemoradiotherapy. However, as in other disease sites, tracer uptake may occasionally persist (usually at mild to moderate intensity) for several months. The underlying reasons include persistent cancer, inflammation, abscess formation, and radionecrosis.

In general, focal and asymmetric ${ }^{18} \mathrm{~F}-\mathrm{FDG}$ uptake with an intensity greater than that in surrounding normal tissues (in particular, muscle) and blood vessels should be considered suggestive of residual disease. On PET/CT, such abnormalities should fuse to the site of the primary disease or lymph nodes (rather than blood vessels, fat tissue, skeletal muscle, or other sites). In contrast, diffuse (nonfocal) ${ }^{18} \mathrm{~F}-\mathrm{FDG}$ uptake within the radiation field is usually an indicator of postradiation inflammation. One of the initial trials that established concurrent chemoradiotherapy in locoregionally advanced HNSCC reported high-grade toxic effects in $82 \%$ of patients, including grade 3 or 4 mucositis in $41 \%$ of patients and laryngeal toxicity in 14\% (5). This report has obvious implications for imaging studies: laryngeal edema and treatment-induced infiltrative changes in perilaryngeal soft tissues are commonly observed on posttreatment CT, along with nonspecific contrast enhancement patterns. Likewise, increased laryngeal or oropharyngeal ${ }^{18} \mathrm{~F}-\mathrm{FDG}$ uptake may be observed for prolonged periods after chemoradiotherapy. In most cases, this uptake will be of mild to moderate intensity and will be diffuse throughout the larynx or along oropharyngeal walls. Again, focal uptake should raise suspicion about ulceration or persistent disease. In view of the relatively high response rates, the fact that persistent disease is uncommon should be considered when one is interpreting PET scans in this setting. Patient examples are shown in Figures 1-3.

Standardized uptake values (SUVs) cannot differentiate reliably between residual cancer and inflammation. In a retrospective analysis, Yao et al. (75) showed that an SUV of 2.9 identified residual disease in neck nodes with a sensitivity of $100 \%$ and a specificity of $97 \%$. However, this finding could not be confirmed in subsequent studies. When applying the same SUV cutoff to a similar patient population, Ong et al. (67) reported a sensitivity of $57 \%$ and specificity of $84 \%$,
FIGURE 1. False-positive PET/CT findings for primary site, right tonsil cancer (T4N2c). PET/CT was performed $14 \mathrm{wk}$ after chemoradiotherapy. Focally intense ${ }^{18} \mathrm{~F}-\mathrm{FDG}$ uptake is seen in right tonsillar fossa, with SUV of 4.7; small ulceration was seen clinically. ${ }^{18} \mathrm{~F}-\mathrm{FDG}$ uptake resolved on follow-up scan 3 mo later. However, this focal pattern of intense uptake is indeed the most characteristic finding in local residual disease.

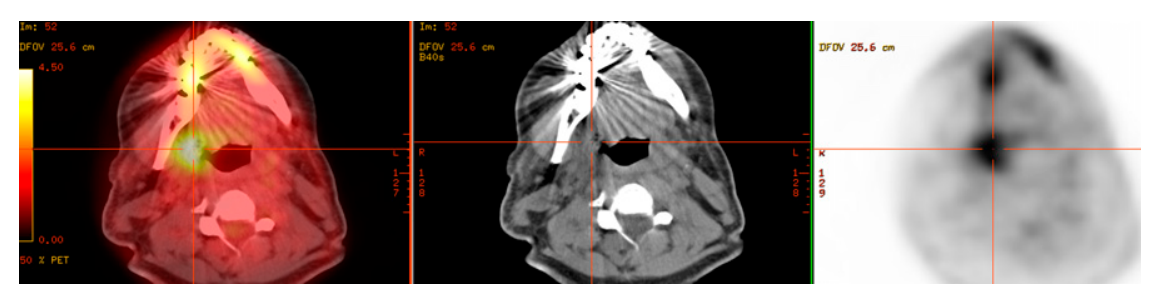



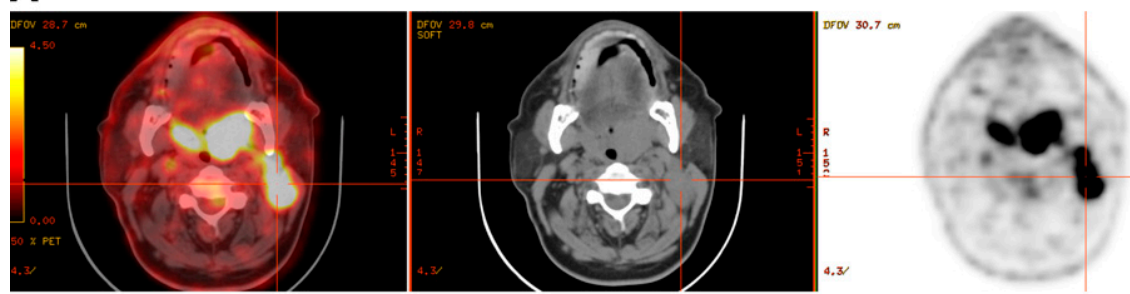

B
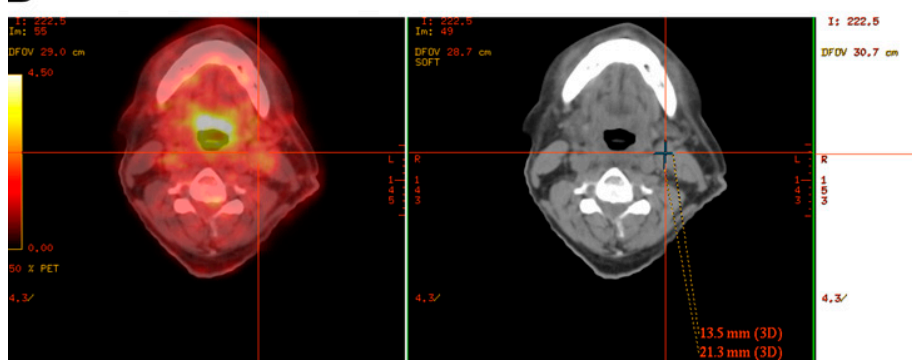

FIGURE 2. True-negative PET/CT findings for T2N2b cancer on left side of base of tongue. (A) Pretherapy scan shows intense ${ }^{18} \mathrm{~F}-\mathrm{FDG}$ uptake in primary tumor and left neck lymphadenopathy. (B) Scan obtained 10 wk after end of chemoradiotherapy shows $13 \times$ $21 \mathrm{~mm}$ lymph node in left neck, level 2 , and mild, diffuse uptake (SUV 2.7) not strictly confined to node.

which were considerably worse than the $71 \%$ sensitivity and $89 \%$ specificity based on visual assessment using the aforementioned criteria. SUVs proposed as suitable cutoffs for the identification of residual cancer based on singleinstitution studies on a specific set of patients may not be applicable to other institutions with different equipment, patient populations, and clinical imaging protocols. It is also unlikely that any sharp cutoff truly exists between malignant and benign SUVs. Looking on the bright side, though, it is reassuring that clinical image interpretation skills and judgment, acquired over many years, cannot be replaced by a computer-generated number.

\section{Impact on Patient Management}

Because clinical parameters and structural imaging cannot reliably predict the presence of residual metastatic neck disease, some investigators still advocate planned neck dissection in all patients with initial N2 or N3 disease (8$10,83,84)$. Historically, the risk for residual cancer in such nodes has exceeded $20 \%$, a number that has been accepted as the lower threshold for surgical intervention. In light of the high NPV of posttreatment ${ }^{18}$ F-FDG PET, this approach may no longer be justified. In one of the previously cited studies (67), planned neck dissection would have been considered in 51 patients because of the presence of residual enlarged lymph nodes, but disease was in fact present in only 7 of them. As shown in Tables 1 and 2, most posttreatment ${ }^{18} \mathrm{~F}$ FDG PET scans even in this subset of patients with more advanced (N2 or N3) nodal disease will be negative with current treatment protocols. Implementing a treatment strategy based on posttherapy PET/CT findings in the study by Ong et al. (67) could have reduced the number of planned neck dissections by $75 \%$ (from 51 to 13 ) while missing disease in 2\% (2/84 heminecks). Other investigators have suggested that negative ${ }^{18} \mathrm{~F}-\mathrm{FDG}$ PET/CT results after chemoradiotherapy could reduce the number of planned neck dissections by more than $80 \%$ (70). Although clinical factors, including the initial nodal stage, remain an important consideration, it would appear that a PET/CT-based strategy might reduce the element of arbitrary decision making in patient management after chemoradiotherapy.

Whereas all of the aforementioned studies were retrospective, the currently ongoing Radiation Therapy Oncology Group Trial 0522 (85) is collecting these data prospectively. Patients with locoregionally advanced HNSCC will be randomized to treatment with cisplatin and radiotherapy, or cisplatin and radiotherapy plus cetuximab. This study primarily aims to determine whether disease-specific survival can be improved with the addition of cetuximab. However, a substudy will also investigate the prognostic and diagnostic utility of ${ }^{18}$ F-FDG PET before and after the end of therapy, and in particular the correlation between posttreatment
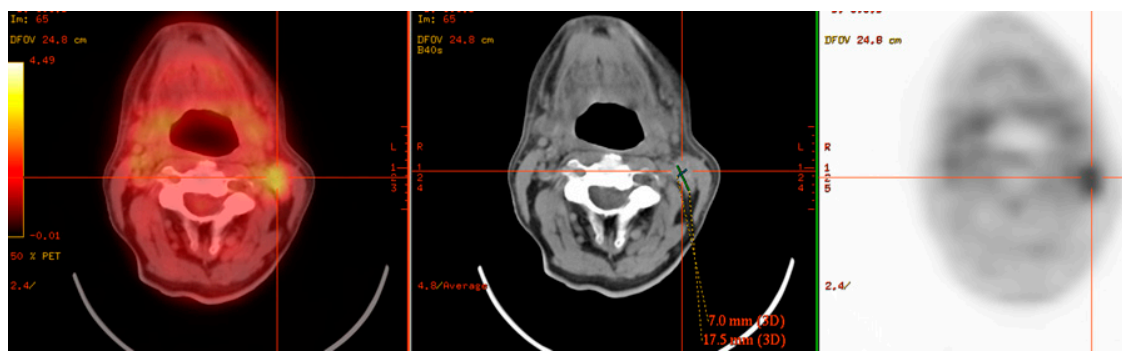

FIGURE 3. True-positive PET/CT findings for lymph node uptake in a case of T2N2a cancer on left side of base of tongue. PET/CT was performed $10 \mathrm{wk}$ after end of chemoradiotherapy. A $7 \times$ $17 \mathrm{~mm}$ lymph node in left neck, level 2, shows focal ${ }^{18} \mathrm{~F}-\mathrm{FDG}$ uptake clearly higher than surrounding background activity, with SUV of 3.2 . 
${ }^{18}$ F-FDG PET findings and nodal response or nodal relapse rates. The organizers hypothesize that negative posttreatment ${ }^{18}$ F-FDG PET results in patients with $\mathrm{N} 2$ or N3 disease indicates a pathologic complete response in more than $85 \%$ of treated necks and, conversely, a low overall nodal relapse rate of $10 \%$ or less. Study results will likely not become available before 2010 .

Several authors have proposed algorithms for patient management after chemoradiotherapy $(67,74,75,86)$. These algorithms differ slightly in their proposed time points for early structural imaging and in the implications of PET findings for subsequent patient management. Some authors $(75,86)$ have proposed the routine use of early $(6-8 \mathrm{wk}$ after the end of therapy) structural imaging to assess the treatment response, followed by a second set of PET and CT studies at 12 wk. We believe that a more measured approach can be taken and recommend early imaging of any kind only if there is a strong clinical suspicion of lack of response or progression (Fig. 4). In particular, it is the consensus opinion of the multidisciplinary head and neck cancer team at Memorial Sloan-Kettering Cancer Center that a dedicated neck CT scan with intravenous contrast material and ${ }^{18} \mathrm{~F}-\mathrm{FDG}$ PET/CT (potentially in a single imaging session) should be performed about 10-12 wk after the end of therapy, unless clinical management requires imaging earlier. This time point strikes a balance between the clinical desire for early, yet accurate, response assessment and the surgeon's desire not to perform a neck dissection on tissues in which extensive fibrosis and scar tissue have developed as the result of chemoradiotherapy. Shrinkage of large nodal masses will take time; early imaging after the end of therapy only causes uncertainty and will rarely provide guidance for management. As shown in Figure 1, patients with no residual abnormal lymph nodes on CT (i.e., diameter $<1 \mathrm{~cm}$ ) can generally be observed, because CT has a high NPV and ${ }^{18}$ F-FDG uptake in these normal-sized nodes is frequently false-positive. Patients with residual lymphadenopathy and abnormal PET findings should undergo neck dissection, possibly in the form of superselective neck dissection, which addresses only 1 or 2 neck levels of concern (87). Management of patients with residual enlarged nodes and negative PET findings should be individualized according to the following considerations: First, negative PET findings have a high NPV, and planned neck dissection is thus unnecessary in most of these cases. However, close follow-up of these patients is required. Second, if close clinical follow-up cannot be guaranteed, or if extenuating circumstances indicate a higher likelihood for local recurrence (e.g., extranodal tumor extension), a neck dissection may be indicated. Third, in any event, the rationale for the chosen approach should be discussed with the patient.

Regarding the optimal time point for follow-up imaging, we believe that PET scans done later than $12 \mathrm{wk}$ after the end of therapy will not be helpful to surgeons attempting to judge the need for a neck dissection. Although these later scans may still provide clinically useful information (e.g., in the surveillance of high-risk patients or in the detection of early recurrence), they do not qualify as a tool for response assessment.

Ideally, the concept that patient management can be decided on the basis of posttherapy PET/CT findings would be tested in a randomized trial comparing outcome data in 2 groups of patients. In one group, planned neck dissection would be performed routinely, whereas in the other group, neck dissection would be performed only when the PET scan result was suggestive; all other patients would be followed clinically. Although a randomized trial may be preferred on scientific grounds, it is unlikely that this will

FIGURE 4. Suggested algorithm for management of HNSCC patients after chemoradiotherapy, based on PET and CT findings obtained approximately 10-12 wk after end of therapy. dz. = disease; ECE = extracapsular extension; iv. = intravenous; $\mathrm{LN}=$ lymph node; ND = neck dissection; PET - = PETnegative; PET $+=$ PET-positive.

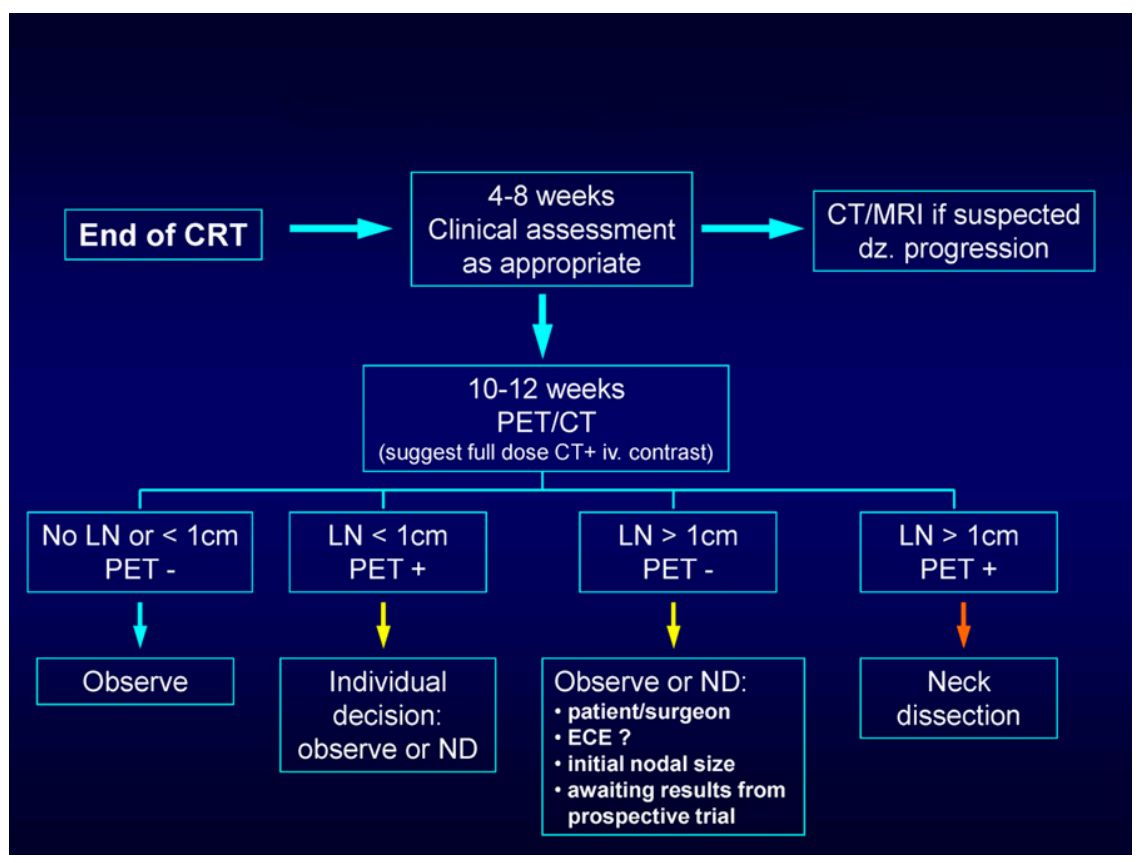


happen, because the available evidence has already begun to shape clinical practice. A reasonable alternative approach would involve a medical team of head and neck cancer specialists (surgeons, oncologists, imaging physicians) that provide a structured plan for close follow-up based on one of the proposed algorithms.

\section{${ }^{18}$ F-FDG PET During Chemoradiotherapy or After Induction Chemotherapy}

The potential clinical utility of PET for early response assessment during chemoradiotherapy has not been studied systematically. Data from other malignancies $(88,89)$ suggest that a significant decline in ${ }^{18} \mathrm{~F}$-FDG uptake between baseline and interim PET after a few cycles of chemo- or chemoradiotherapy may indicate a better prognosis and high likelihood for achieving a complete response. Only a single small study has attempted to address this question in HNSCC (90). Using coincidence camera imaging, that study noted an early and significant decline in ${ }^{18} \mathrm{~F}$-FDG uptake in 47 patients with locally advanced disease after a cycle of chemotherapy or $24 \mathrm{~Gy}$ of radiotherapy. When dichotomized by the median SUV, individuals with lower ${ }^{18} \mathrm{~F}$-FDG uptake showed a better rate of locoregional control. However, a closer analysis of the study reveals that similar prognostic information could also be derived from the baseline scan alone. Although interesting, the study remains therefore largely inconclusive. In particular, it remains unclear at what interim time point during the course of therapy a PET scan should be performed and how interim PET findings might alter patient management (good local control rates with concurrent chemoradiotherapy, lack of an established alternate therapy).

There are also limited data on the role of PET in assessing the response to induction chemotherapy before subsequent concurrent chemoradiotherapy. This is a topic of growing interest to medical oncologists. Proponents of this approach believe that it may improve clinical outcome in locoregionally advanced HNSCC. For instance, in the DeCIDE trial, patients with $\mathrm{N} 2$ or $\mathrm{N} 3$ disease will be randomized to treatment with standard concurrent chemoradiotherapy or induction chemotherapy followed by chemoradiotherapy. The effect on overall and progression-free survival, rate of distant metastases, and quality of life will be compared (91). Other currently ongoing studies in the United States and Europe will apply induction chemotherapy followed by radiotherapy in combination with cisplatin or a biologic agent such as cetuximab $(92,93)$. In the future, it will be important to identify patients who might benefit from this new treatment approach. It is conceivable that PET with either ${ }^{18} \mathrm{~F}-\mathrm{FDG}$ or ${ }^{18} \mathrm{~F}-3{ }^{\prime}$-deoxy-3' fluorothymidine (FLT) after induction chemotherapy might help in this decision. For instance, if a patient shows little or no metabolic response after induction chemotherapy, this might indicate a low likelihood for cure with subsequent chemoradiotherapy; perhaps such patients would benefit from immediate salvage surgery after induction therapy or should be enrolled in more aggressive chemoradiotherapy protocols.
${ }^{18}$ F-FDG PET After Surgery and Before Adjuvant Therapy

Shintani et al. (94) investigated the role of ${ }^{18} \mathrm{~F}-\mathrm{FDG}$ PET/ CT early after surgical resection and before planned adjuvant radiotherapy in a heterogeneous group of 91 patients (62 with squamous cell carcinoma). PET/CT approximately $28 \mathrm{~d}$ after surgery revealed findings suggestive of residual macroscopic tumor in 24 of the 91 individuals (26\%). Subsequent biopsies proving residual cancer in $45 \%$ of these instances (PPV, $45 \%$ ) led to a change in management in 14 patients $(15 \%)$, including abandonment of adjuvant radiotherapy and a switch to palliative chemotherapy, as well as changes in radiation field or dose. Imaging early after surgery obviously causes a high rate of false-positive findings; the exact role of PET/CT, if any, remains to be defined. However, it is clear that combined PET/CT (rather than PET only) should be performed to enable precise target definition for radiotherapy in HNSCC (95).

\section{A POTENTIAL ROLE FOR OTHER PET RADIOTRACERS}

\section{Amino Acid Transport and Protein Synthesis}

PET with labeled amino acids has been applied to head and neck cancer. Despite the excitement generated by earlier studies, no tracer of amino acid transport or protein synthesis has been tested rigorously in HNSCC. ${ }^{11} \mathrm{C}$-methionine did not provide any clear benefits over imaging with ${ }^{18} \mathrm{~F}-\mathrm{FDG}$. The short half-life of ${ }^{11} \mathrm{C}$ requires a nearby cyclotron, and the image quality is suboptimal. False-positive uptake at sites of inflammation can occur with this agent and with other amino acids. It is doubtful that any of these agents will have a future in the clinical response assessment of patients with HNSCC.

${ }^{18} \mathrm{~F}-\mathrm{FLT}$

${ }^{18}$ F-FLT uptake and retention require a functional nucleoside transporter in the plasma membrane and activity of the thymidine kinase- 1 enzyme (96). In vitro, ${ }^{18}$ F-FLT retention correlates with the fraction of cells in the S-phase of the cell cycle and with thymidine kinase- 1 activity $(97,98)$. Thymidine kinase- 1 is inhibited by many chemotherapeutic drugs and by external-beam irradiation (97). When tumor cells are irradiated, they do not enter the cell cycle but instead remain in the S-phase (97). In vitro, a radiation dose-dependent decrease in ${ }^{18} \mathrm{~F}$-FLT uptake that paralleled the decline of the fraction of cells in the S-phase was shown (98). Decreases in ${ }^{18}$ F-FLT uptake and thymidine kinase-1 activity were observed within $24 \mathrm{~h}$ after irradiation.

The clinical utility of ${ }^{18}$ F-FLT in clinical response assessment in HNSCC is under investigation. From studies on other malignancies (99) it might be inferred that ${ }^{18}$ F-FLT imaging could potentially permit an earlier or more accurate response assessment in HNSCC than can imaging with ${ }^{18} \mathrm{~F}-\mathrm{FDG}$ or CT/MRI. However, preliminary experimental studies have shown mixed results. When nude mice bearing the human squamous cell cancer graft (HNX-OE; nu/nu mice) were irradiated, both ${ }^{18} \mathrm{~F}$-FDG and ${ }^{18} \mathrm{~F}$-FLT uptake declined from baseline levels, but the decline in ${ }^{18} \mathrm{~F}$-FDG uptake occurred mainly during the first week of treatment, whereas the 
greatest decline in ${ }^{18} \mathrm{~F}$-FLT uptake was noted during the second treatment week (100). In another study, however, ${ }^{18} \mathrm{~F}$ FLT PET showed promise in assessing the early response to cetuximab in a squamous cell cancer xenograft model (101). A significant decline in tumor SUV, tumor-to-muscle ratios, and thymidine kinase- 1 activity occurred as early as $6 \mathrm{~d}$ after single-agent therapy had been initiated with cetuximab. In the clinic, these early changes might be helpful in assessing the response to cetuximab monotherapy during the induction phase for subsequent combination chemotherapy or chemoradiotherapy. Of note, false-positive ${ }^{18}$ F-FLT uptake can occur in reactive lymph nodes (102) and is a particular problem after concurrent chemoradiotherapy. The frequency of falsepositive ${ }^{18} \mathrm{~F}$-FLT uptake during or after chemoradiotherapy in patients with HNSCC has not been established. If this were indeed a common phenomenon, it would severely limit the utility of this tracer for response assessment.

\section{Hypoxia Imaging}

Tumor hypoxia is a common phenomenon in HNSCC (103-105). Hypoxic cells are resistant to the cytotoxic effects of chemotherapy and ionizing radiation (106-109) and require radiation doses up to 3 times higher than for the same level of cell inactivation relative to the same cells under normoxic conditions. A recent review of nearly $400 \mathrm{HNSCC}$ patients who underwent tumor oxygenation measurement demonstrated that hypoxia was strongly associated with treatment failure (locoregional recurrence and distant metastasis) independently of stage and therapeutic modality (105). This observation has led to a growing interest in diagnosing hypoxic HNSCC before therapy in the hope of applying novel treatment strategies that may overcome the resistance to conventional chemoradiotherapy. Several compounds are available for the imaging of hypoxia $(109,110)$. Currently, ${ }^{18} \mathrm{~F}$-fluoromisonidazole ( ${ }^{18} \mathrm{~F}$-FMISO) is still considered the standard PET tracer for hypoxia imaging. One goal of hypoxia imaging is the identification of patients with hypoxic tumors who may benefit from a combination therapy of irradiation with radiation sensitizers (111), vasodilators, or carbogen breathing, as was used in the ARCON (accelerated radiotherapy with carbogen and nicotinamide) trial in advanced head and neck cancer (112), or hypoxic cell cytotoxins such as tirapazamine. Whereas the nonselective addition of tirapazamine to standard chemoradiotherapy did not improve clinical outcome in a randomized phase III trial (HEADSTART) (113), an improvement in locoregional control rates could be shown in selected patients with evidence of tumor hypoxia on ${ }^{18}$ F-FMISO PET (114). However, some recent data suggest that hypoxia as shown on FMISO PET may be overcome in most patients even with standard chemoradiotherapy (115). Four weeks into treatment, only 2 of 20 patients showed imaging evidence of persistent hypoxia on the ${ }^{18} \mathrm{~F}-\mathrm{FMISO}$ scan, and local recurrence did not develop in these 2 patients. With a median follow-up of $36 \mathrm{mo}$, the $3-y$ progression-free survival in this patient population was $95 \%$. The frequency and time course at which tumor hypoxia persists after the initiation of chemoradiotherapy are unknown. It is conceivable that treatment outcome can be improved, despite the presence of hypoxia, with certain combinations of standard chemotherapy and irradiation. However, if interventions aimed at overcoming tumor hypoxia are used as part of the experimental protocol, they should probably center on the first 4 wk of therapy.

\section{Imaging EGFR and Response to EGFR Inhibitors}

Neither clinical presentation nor immunohistochemical analysis of tumor specimens can reliably predict the therapeutic response to EGFR inhibitors. A high EGFR gene copy in tumor specimens may identify patients with a increased likelihood of response, and a decline in phosphorylated EGFR levels in skin biopsies during therapy has been suggested as a potential surrogate marker for improved clinical outcome (116). However, the latter reflects only a systemic drug effect or toxicity and does not provide any information about local drug concentrations or about the effect on the tumor itself.

Clinical response can certainly be assessed nonspecifically with ${ }^{18} \mathrm{~F}$-FDG PET $(117,118)$. Downregulation of ${ }^{18} \mathrm{~F}-\mathrm{FDG}$ uptake after treatment with small-molecule tyrosine kinase inhibitors, such as gefitinib, seems to be an early phenomenon (119) that precedes changes on structural imaging. More specific imaging tests based on the increasing recognition of the molecular structure of receptors and tumor pathways are being developed. Signal transduction through EGFR requires ligand binding to the receptor, dimerization of ligandreceptor complexes, and autophosphorylation of the receptor at the intracellular tyrosine kinase domain. In principle, at least 2 of these steps can be imaged, and such imaging might be helpful in predicting and monitoring treatment response. For instance, one radiolabeled ligand for EGFR, the chelate complex ${ }^{64} \mathrm{Cu}$-DOTA-cetuximab, has been tested in smallanimal studies correlating tracer uptake on small-animal PET with EGFR expression in Western blot analysis (120). Another group of tracers, radiolabeled anilinoquinazolines, bind to the intracellular adenosine triphosphate binding pocket of the receptor kinase; agents that bind irreversibly at this site and are labeled with ${ }^{11} \mathrm{C}$ or ${ }^{124} \mathrm{I}$ appear suitable for PET $(121,122)$. It is hoped that clinical PET studies with these or similar compounds may help in selecting patients who are likely to respond to EGFR inhibitors and in monitoring the drug response in a specific manner.

\section{Imaging of Angiogenesis and Angiogenesis Inhibitors}

It is currently unclear which patients may particularly benefit from treatment with angiogenesis-inhibiting drugs. Although elevated VEGF serum levels are a marker of poor prognosis in HNSCC, they cannot predict the clinical response to antiangiogenic therapies (123). First, VEGF is produced not only by tumor cells but also by normal platelets, cells in the tumor-surrounding stroma, and other cells in the body; second, VEGF receptors are found primarily on endothelial cells but also on various tumor cells; third, resistance to VEGF inhibitors can exist intrinsically or may develop 
during therapy (e.g., due to upregulation of other angiogenic receptors or an increase in circulating endothelial progenitor cells) (123). Because inhibition of angiogenesis per se may not cause cell death and tumor shrinkage (but instead "only" prevent further growth), it is also unclear how the efficacy of angiogenesis inhibitors could best be shown and monitored in the clinical setting (rather than inferring efficacy indirectly from achieving stable disease).

Changes in tumor hyperemia can be documented on contrast-enhanced CT and MRI or dedicated MRI perfusion sequences. However, more specific imaging tests documenting drug targeting and effect are available. One example is the radiotracer ${ }^{18} \mathrm{~F}-\mathrm{RGD}$ peptide $(124,125)$, which binds specifically to $\alpha_{\nu} \beta_{3}$ integrins expressed at the surface of activated endothelial cells during angiogenesis (126). The intensity of ${ }^{18} \mathrm{~F}-\mathrm{RGD}$ peptide accumulation correlates with the presence of activated endothelial cells and, quantitatively, with microvessel density (124). ${ }^{18} \mathrm{~F}$-RGD peptide imaging of HNSCC is feasible (127): In a pilot study of 11 patients, tracer uptake was detected in 10 of 12 primary lesions (SUV, 2.2-5.8) with reasonable contrast, based on a tumor-to-blood ratio of $2.8 \pm$ 1.1. Two tumors that were smaller than $5 \mathrm{~mm}$ were missed. Immunohistochemistry confirmed $\alpha_{v} \beta_{3}$ expression on microvessels in all tumors. This or similar radiotracers might potentially be useful in identifying suitable patients for treatment with antiangiogenic drugs and in monitoring the response to such therapies in a drug-specific manner (instead of, or in addition to, tumor shrinkage or a decline in glucose metabolism).

\section{Treatment Options on the Horizon}

Cancer gene therapy, whereby replication-incompetent viral vectors are used to transfer a therapeutic gene into the cancer cell, is under study in many malignancies, including HNSCC (128). Another treatment option is the use of oncolytic viruses, which infect, multiply within, and subsequently lyse cancer cells. The attenuated adenovirus ONYX015 , which preferentially localizes in cells lacking the tumor suppressor gene $\mathrm{p} 53$, has been tested clinically. In a phase II trial, intratumoral ONYX-015 injection led to a complete or partial $(<50 \%$ reduction in tumor diameter) response in $20 \%$ of cases (129). Other oncolytic viruses are under investigation. An attenuated, replication-competent, oncolytic herpes simplex virus (NV1023) has shown promise in experimental studies. NV 1023 delivery to the surgical bed after tumor resection caused viral infection of metastatic squamous cells in cervical lymph nodes and improved the rate of locoregional control and disease-free survival (130). Localization, distribution, and survival of this oncolytic virus was imaged with ${ }^{18} \mathrm{~F}-2$ '-fluoro-2'-deoxy-1- $\beta$-D- $\beta$-arabinofuranosyl-5ethyluracil PET, taking advantage of viral thymidine kinase expression (131). One can envision similar imaging studies in the clinical environment, which may be particularly useful when the agent is to be administered intravenously rather than into the tumor site.

\section{CONCLUSION}

Concurrent chemoradiotherapy is widely used as the definitive treatment for locoregionally advanced HNSCC because it provides higher response rates than radiotherapy alone. Negative ${ }^{18}$ F-FDG PET or PET/CT findings after concurrent chemoradiotherapy have a high NPV $(>95 \%)$. The PPV is lower, but few studies will be considered positive when interpreted as suggested in this review. On the basis of a patient's specific condition, neck dissection may be avoided in many cases. The role of PET with either ${ }^{18} \mathrm{~F}-\mathrm{FDG}$ or ${ }^{18} \mathrm{~F}-$ FLT in assessing response during induction or definitive chemoradiotherapy is under investigation. Experimental therapy with EGFR and VEGF inhibitors is under study in HNSCC; several PET probes appear promising for measuring the response to these new drugs and potentially for selecting patients with suitable molecular targets for such experimental therapies. Hypoxia imaging may be helpful in designing alternate radiotherapy techniques that may overcome the radioresistance of hypoxic tumors. For most clinical purposes, however, ${ }^{18} \mathrm{~F}$-FDG PET/CT will remain the major clinical tool for monitoring treatment in HNSCC in the near future.

\section{ACKNOWLEDGMENTS}

We thank John Humm, for helpful discussions on radiation biology, and Richard Wong, for helpful discussions on oncolytic virus treatment for head and neck cancer.

\section{REFERENCES}

1. Jemal A, Siegel R, Ward E, et al. Cancer statistics, 2008. CA Cancer J Clin. 2008;58:71-96.

2. Cooper JS, Pajak TF, Forastiere AA, et al. Postoperative concurrent radiotherapy and chemotherapy for high-risk squamous-cell carcinoma of the head and neck. N Engl J Med. 2004;350:1937-1944.

3. Bernier J, Domenge C, Ozsahin M, et al. Postoperative irradiation with or without concomitant chemotherapy for locally advanced head and neck cancer. N Engl J Med. 2004;350:1945-1952.

4. Bernier J, Cooper JS, Pajak TF, et al. Defining risk levels in locally advanced head and neck cancers: a comparative analysis of concurrent postoperative radiation plus chemotherapy trials of the EORTC (\#22931) and RTOG (\# 9501). Head Neck. 2005;27:843-850.

5. Forastiere AA, Goepfert H, Maor M, et al. Concurrent chemotherapy and radiotherapy for organ preservation in advanced laryngeal cancer. $N$ Engl $J$ Med. 2003;349:2091-2098.

6. Denis F, Garaud P, Bardet E, et al. Final results of the 94-01 French Head and Neck Oncology and Radiotherapy Group randomized trial comparing radiotherapy alone with concomitant radiochemotherapy in advanced-stage oropharynx carcinoma. J Clin Oncol. 2004;22:69-76.

7. Adelstein DJ, Li Y, Adams GL, et al. An intergroup phase III comparison of standard radiation therapy and two schedules of concurrent chemoradiotherapy in patients with unresectable squamous cell head and neck cancer. J Clin Oncol. 2003;21:92-98.

8. McHam SA, Adelstein DJ, Rybicki LA, et al. Who merits a neck dissection after definitive chemoradiotherapy for N2-N3 squamous cell head and neck cancer? Head Neck. 2003;25:791-798.

9. Brizel DM, Prosnitz RG, Hunter S, et al. Necessity for adjuvant neck dissection in setting of concurrent chemoradiation for advanced head-and-neck cancer. Int J Radiat Oncol Biol Phys. 2004;58:1418-1423.

10. Frank DK, Hu KS, Culliney BE, et al. Planned neck dissection after concomitant radiochemotherapy for advanced head and neck cancer. Laryngoscope. 2005;115:1015-1020.

11. Argiris A, Stenson KM, Brockstein BE, et al. Neck dissection in the combinedmodality therapy of patients with locoregionally advanced head and neck cancer. Head Neck. 2004;26:447-455. 
12. Mendenhall WM, Million RR, Cassisi NJ. Squamous cell carcinoma of the head and neck treated with radiation therapy: the role of neck dissection for clinically positive neck nodes. Int J Radiat Oncol Biol Phys. 1986;12:733-740.

13. Boyd TS, Harari PM, Tannehill SP, et al. Planned postradiotherapy neck dissection in patients with advanced head and neck cancer. Head Neck. 1998;20:132-137.

14. Lee HJ, Zelefsky MJ, Kraus DH, et al. Long-term regional control after radiation therapy and neck dissection for base of tongue carcinoma. Int $J$ Radiat Oncol Biol Phys. 1997;38:995-1000.

15. Lavertu P, Adelstein DJ, Saxton JP, et al. Management of the neck in a randomized trial comparing concurrent chemotherapy and radiotherapy with radiotherapy alone in resectable stage III and IV squamous cell head and neck cancer. Head Neck. 1997;19:559-566.

16. Spencer SA, Harris J, Wheeler RH, et al. Final report of RTOG 9610, a multiinstitutional trial of reirradiation and chemotherapy for unresectable recurrent squamous cell carcinoma of the head and neck. Head Neck. 2008;30:281-288.

17. Sulman EP, Schwartz DL, Le TT, et al. IMRT reirradiation of head and neck cancer: disease control and morbidity outcomes. Int J Radiat Oncol Biol Phys. 2009;73:399-409.

18. Langer CJ, Harris J, Horwitz EM, et al. Phase II study of low-dose paclitaxel and cisplatin in combination with split-course concomitant twice-daily reirradiation in recurrent squamous cell carcinoma of the head and neck: results of Radiation Therapy Oncology Group Protocol 9911. J Clin Oncol. 2007; 25:4800-4805.

19. Lee N, Chan K, Bekelman JE, et al. Salvage re-irradiation for recurrent head and neck cancer. Int J Radiat Oncol Biol Phys. 2007;68:731-740.

20. Folkman J. Angiogenesis in cancer, vascular, rheumatoid and other disease. Nat Med. 1995;1:27-31.

21. Holmgren L, O'Reilly MS, Folkman J. Dormancy of micrometastases: balanced proliferation and apoptosis in the presence of angiogenesis suppression. Nat Med. 1995;1:149-153.

22. Naumov GN, Akslen LA, Folkman J. Role of angiogenesis in human tumor dormancy: animal models of the angiogenic switch. Cell Cycle. 2006;5:17791787.

23. Folkman J. Angiogenesis. Annu Rev Med. 2006;57:1-18.

24. Jain RK. Normalization of tumor vasculature: an emerging concept in antiangiogenic therapy. Science. 2005;307:58-62.

25. Arany Z, Foo SY, Ma Y, et al. HIF-independent regulation of VEGF and angiogenesis by the transcriptional coactivator PGC-1alpha. Nature. 2008;451:1008-1012.

26. Denko NC. Hypoxia, HIF1 and glucose metabolism in the solid tumour. Nat Rev Cancer. 2008.

27. Cao Y, Linden P, Shima D, Browne F, Folkman J. In vivo angiogenic activity and hypoxia induction of heterodimers of placenta growth factor/vascular endothelial growth factor. J Clin Invest. 1996;98:2507-2511.

28. Liao D, Johnson RS. Hypoxia: a key regulator of angiogenesis in cancer. Cancer Metastasis Rev. 2007;26:281-290.

29. Liao D, Corle C, Seagroves TN, Johnson RS. Hypoxia-inducible factor-1alpha is a key regulator of metastasis in a transgenic model of cancer initiation and progression. Cancer Res. 2007;67:563-572.

30. Li XF, Carlin S, Urano M, Russell J, Ling CC, O’Donoghue JA. Visualization of hypoxia in microscopic tumors by immunofluorescent microscopy. Cancer Res. 2007;67:7646-7653.

31. Mizukami Y, Kohgo Y, Chung DC. Hypoxia inducible factor-1 independent pathways in tumor angiogenesis. Clin Cancer Res. 2007;13:5670-5674.

32. Folkman J. Angiogenesis: an organizing principle for drug discovery? Nat Rev Drug Discov. 2007;6:273-286.

33. Seiwert TY, Cohen EE. Targeting angiogenesis in head and neck cancer. Semin Oncol. 2008;35:274-285.

34. Shemirani B, Crowe DL. Head and neck squamous cell carcinoma lines produce biologically active angiogenic factors. Oral Oncol. 2000;36:61-66.

35. Riedel F, Gotte K, Schwalb J, Wirtz H, Bergler W, Hormann K. Serum levels of vascular endothelial growth factor in patients with head and neck cancer. Eur Arch Otorhinolaryngol. 2000;257:332-336.

36. Kyzas PA, Stefanou D, Batistatou A, Agnantis NJ. Prognostic significance of VEGF immunohistochemical expression and tumor angiogenesis in head and neck squamous cell carcinoma. J Cancer Res Clin Oncol. 2005;131:624-630.

37. Smith BD, Smith GL, Carter D, Sasaki CT, Haffty BG. Prognostic significance of vascular endothelial growth factor protein levels in oral and oropharyngeal squamous cell carcinoma. J Clin Oncol. 2000;18:2046-2052.

38. Kyzas PA, Cunha IW, Ioannidis JP. Prognostic significance of vascular endothelial growth factor immunohistochemical expression in head and neck squamous cell carcinoma: a meta-analysis. Clin Cancer Res. 2005;11:14341440 .
39. ClinicalTrials.gov. Cisplatin, bevacizumab, and intensity-modulated radiation therapy in treating patients with stage III or stage IV head and neck cancer. ClinicalTrials.gov identifier NCT00423930. Available at: http://clinicaltrials. gov/ct $2 /$ show $/$ NCT00423930?term $=$ head + and + neck + cancer\&recr $=$ Open $\&$ rank=26. Accessed March 27, 2009.

40. Fury MG, Zahalsky A, Wong R, et al. A phase II study of SU5416 in patients with advanced or recurrent head and neck cancers. Invest New Drugs. 2007;25:165-172.

41. Bozec A, Gros FX, Penault-Llorca F, et al. Vertical VEGF targeting: a combination of ligand blockade with receptor tyrosine kinase inhibition. Eur J Cancer. 2008;44:1922-1930.

42. Bozec A, Formento P, Lassalle S, Lippens C, Hofman P, Milano G. Dual inhibition of EGFR and VEGFR pathways in combination with irradiation: antitumour supra-additive effects on human head and neck cancer xenografts. Br J Cancer. 2007;97:65-72.

43. Bozec A, Sudaka A, Fischel JL, Brunstein MC, Etienne-Grimaldi MC, Milano G. Combined effects of bevacizumab with erlotinib and irradiation: a preclinical study on a head and neck cancer orthotopic model. Br J Cancer. 2008;99:93-99.

44. Gorski DH, Beckett MA, Jaskowiak NT, et al. Blockage of the vascular endothelial growth factor stress response increases the antitumor effects of ionizing radiation. Cancer Res. 1999;59:3374-3378.

45. Grandis JR, Tweardy DJ. Elevated levels of transforming growth factor alpha and epidermal growth factor receptor messenger RNA are early markers of carcinogenesis in head and neck cancer. Cancer Res. 1993;53:3579-3584.

46. Ang KK, Berkey BA, Tu X, et al. Impact of epidermal growth factor receptor expression on survival and pattern of relapse in patients with advanced head and neck carcinoma. Cancer Res. 2002;62:7350-7356.

47. Hitt R, Ciruelos E, Amador ML, et al. Prognostic value of the epidermal growth factor receptor (EGRF) and p53 in advanced head and neck squamous cell carcinoma patients treated with induction chemotherapy. Eur J Cancer. 2005;41:453-460.

48. Chung $\mathrm{CH}$, Ely $\mathrm{K}, \mathrm{McGavran} \mathrm{L}$, et al. Increased epidermal growth factor receptor gene copy number is associated with poor prognosis in head and neck squamous cell carcinomas. J Clin Oncol. 2006;24:4170-4176.

49. Psyrri A, Yu Z, Weinberger PM, et al. Quantitative determination of nuclear and cytoplasmic epidermal growth factor receptor expression in oropharyngeal squamous cell cancer by using automated quantitative analysis. Clin Cancer Res. 2005;11:5856-5862.

50. Temam S, Kawaguchi H, El-Naggar AK, et al. Epidermal growth factor receptor copy number alterations correlate with poor clinical outcome in patients with head and neck squamous cancer. J Clin Oncol. 2007;25:2164-2170.

51. Cohen EE. Role of epidermal growth factor receptor pathway-targeted therapy in patients with recurrent and/or metastatic squamous cell carcinoma of the head and neck. J Clin Oncol. 2006;24:2659-2665.

52. Mendelsohn J, Baselga J. Status of epidermal growth factor receptor antagonists in the biology and treatment of cancer. J Clin Oncol. 2003;21:2787-2799.

53. Burtness B, Goldwasser MA, Flood W, Mattar B, Forastiere AA. Phase III randomized trial of cisplatin plus placebo compared with cisplatin plus cetuximab in metastatic/recurrent head and neck cancer: an Eastern Cooperative Oncology Group study. J Clin Oncol. 2005;23:8646-8654.

54. Bourhis J, Rivera F, Mesia R, et al. Phase I/II study of cetuximab in combination with cisplatin or carboplatin and fluorouracil in patients with recurrent or metastatic squamous cell carcinoma of the head and neck. $J$ Clin Oncol. 2006;24:2866-2872.

55. Baselga J, Trigo JM, Bourhis J, et al. Phase II multicenter study of the antiepidermal growth factor receptor monoclonal antibody cetuximab in combination with platinum-based chemotherapy in patients with platinumrefractory metastatic and/or recurrent squamous cell carcinoma of the head and neck. J Clin Oncol. 2005;23:5568-5577.

56. Herbst RS, Arquette M, Shin DM, et al. Phase II multicenter study of the epidermal growth factor receptor antibody cetuximab and cisplatin for recurrent and refractory squamous cell carcinoma of the head and neck. J Clin Oncol. 2005;23:5578-5587.

57. Vermorken JB, Trigo J, Hitt R, et al. Open-label, uncontrolled, multicenter phase II study to evaluate the efficacy and toxicity of cetuximab as a single agent in patients with recurrent and/or metastatic squamous cell carcinoma of the head and neck who failed to respond to platinum-based therapy. J Clin Oncol. 2007;25:2171-2177.

58. Vermorken JB, Mesia R, Rivera F, et al. Platinum-based chemotherapy plus cetuximab in head and neck cancer. N Engl J Med. 2008;359:1116-1127.

59. Bonner JA, Harari PM, Giralt J, et al. Radiotherapy plus cetuximab for squamous-cell carcinoma of the head and neck. N Engl J Med. 2006;354:567578. 
60. ClinicalTrials.gov. TPF plus cisplatin and radiotherapy vs TPF plus cetuximab and radiotherapy to treat head and neck cancer. ClinicalTrials.gov identifier NCT00716391. Available at: http://clinicaltrials.gov/ct2/show/NCT00716391? term $=$ head + and + neck + cancer\&recr $=$ Open\&rank $=10$. Accessed March 27, 2009.

61. ClinicalTrials.gov. Radiation therapy and cisplatin with or without cetuximab in treating patients with stage III or stage IV head and neck cancer. ClinicalTrials.gov identifier NCT00265941. Available at: http://clinicaltrials. gov/ct $2 /$ show/NCT00265941 term $=$ head + and + neck + cancer $\&$ recr $=$ Open $\&$ rank $=48$. Accessed March 27, 2009.

62. Soulieres D, Senzer NN, Vokes EE, Hidalgo M, Agarwala SS, Siu LL. Multicenter phase II study of erlotinib, an oral epidermal growth factor receptor tyrosine kinase inhibitor, in patients with recurrent or metastatic squamous cell cancer of the head and neck. J Clin Oncol. 2004;22:77-85.

63. Cohen EE, Kane MA, List MA, et al. Phase II trial of gefitinib $250 \mathrm{mg}$ daily in patients with recurrent and/or metastatic squamous cell carcinoma of the head and neck. Clin Cancer Res. 2005;11:8418-8424.

64. Siu LL, Soulieres D, Chen EX, et al. Phase I/II trial of erlotinib and cisplatin in patients with recurrent or metastatic squamous cell carcinoma of the head and neck: a Princess Margaret Hospital phase II consortium and National Cancer Institute of Canada Clinical Trials Group Study. J Clin Oncol. 2007;25:2178-2183.

65. McCollum AD, Burrell SC, Haddad RI, et al. Positron emission tomography with ${ }^{18} \mathrm{~F}$-fluorodeoxyglucose to predict pathologic response after induction chemotherapy and definitive chemoradiotherapy in head and neck cancer. Head Neck. 2004;26:890-896.

66. Yao M, Graham MM, Smith RB, et al. Value of FDG PET in assessment of treatment response and surveillance in head-and-neck cancer patients after intensity modulated radiation treatment: a preliminary report. Int $J$ Radiat Oncol Biol Phys. 2004;60:1410-1418.

67. Ong SC, Schoder H, Lee NY, et al. Clinical utility of ${ }^{18}$ F-FDG PET/CT in assessing the neck after concurrent chemoradiotherapy for locoregional advanced head and neck cancer. $J$ Nucl Med. 2008;49:532-540.

68. Andrade RS, Heron DE, Degirmenci B, et al. Posttreatment assessment of response using FDG-PET/CT for patients treated with definitive radiation therapy for head and neck cancers. Int J Radiat Oncol Biol Phys. 2006;65:1315-1322.

69. Gourin CG, Williams HT, Seabolt WN, Herdman AV, Howington JW, Terris DJ. Utility of positron emission tomography-computed tomography in identification of residual nodal disease after chemoradiation for advanced head and neck cancer. Laryngoscope. 2006;116:705-710.

70. Nayak JV, Walvekar RR, Andrade RS, et al. Deferring planned neck dissection following chemoradiation for stage IV head and neck cancer: the utility of PETCT. Laryngoscope. 2007;117:2129-2134.

71. Schoder H, Yeung HW, Gonen M, Kraus D, Larson SM. Head and neck cancer: clinical usefulness and accuracy of PET/CT image fusion. Radiology. 2004;231:65-72.

72. Branstetter BF IV, Blodgett TM, Zimmer LA, et al. Head and neck malignancy: is PET/CT more accurate than PET or CT alone? Radiology. 2005;235:580-586.

73. Goerres GW, Schmid DT, Bandhauer F, et al. Positron emission tomography in the early follow-up of advanced head and neck cancer. Arch Otolaryngol Head Neck Surg. 2004;130:105-109.

74. Porceddu SV, Jarmolowski E, Hicks RJ, et al. Utility of positron emission tomography for the detection of disease in residual neck nodes after (chemo)radiotherapy in head and neck cancer. Head Neck. 2005;27:175-181.

75. Yao M, Smith RB, Graham MM, et al. The role of FDG PET in management of neck metastasis from head-and-neck cancer after definitive radiation treatment. Int J Radiat Oncol Biol Phys. 2005;63:991-999.

76. Lonneux M, Lawson G, Ide C, Bausart R, Remacle M, Pauwels S. Positron emission tomography with fluorodeoxyglucose for suspected head and neck tumor recurrence in the symptomatic patient. Laryngoscope. 2000;110:1493-1497.

77. Greven KM, Williams DW III, McGuirt WF Sr, et al. Serial positron emission tomography scans following radiation therapy of patients with head and neck cancer. Head Neck. 2001;23:942-946.

78. Forrester HB, Albright N, Ling CC, Dewey WC. Computerized video timelapse analysis of apoptosis of REC:Myc cells x-irradiated in different phases of the cell cycle. Radiat Res. 2000;154:625-639.

79. Luce A, Courtin A, Levalois C, et al. Death receptor pathways mediate targeted and non-targeted effects of ionizing radiations in breast cancer cells. Carcinogenesis. 2009;30:432-439.

80. Dornfeld K, Hopkins S, Simmons J, et al. Posttreatment FDG-PET uptake in the supraglottic and glottic larynx correlates with decreased quality of life after chemoradiotherapy. Int J Radiat Oncol Biol Phys. 2008;71:386-392.

81. Connell CA, Corry J, Milner AD, et al. Clinical impact of, and prognostic stratification by, F-18 FDG PET/CT in head and neck mucosal squamous cell carcinoma. Head Neck. 2007;29:986-995.
82. Fleming AJ Jr, Smith SP Jr, Paul CM, et al. Impact of $\left[{ }^{18} \mathrm{~F}\right]$-2-fluorodeoxyglucose-positron emission tomography/computed tomography on previously untreated head and neck cancer patients. Laryngoscope. 2007;117:1173-1179.

83. Sanguineti G, Corvo R, Benasso M, et al. Management of the neck after alternating chemoradiotherapy for advanced head and neck cancer. Head Neck. 1999;21:223-228.

84. Velazquez RA, McGuff HS, Sycamore D, Miller FR. The role of computed tomographic scans in the management of the N-positive neck in head and neck squamous cell carcinoma after chemoradiotherapy. Arch Otolaryngol Head Neck Surg. 2004;130:74-77.

85. Radiation Therapy Oncology Group (RTOG 0522): A randomized phase III trial of concurrent accelerated radiation and cisplatin versus concurrent accelerated radiation, cisplatin and cetuximab (C225) (followed by surgery for selected patients) for stage III and IV head and neck carcinomas. Available at: http://www.rtog.org/members/protocols/0522/0522.pdf. Accessed March 27, 2009.

86. Quon A, Fischbein NJ, McDougall IR, et al. Clinical role of ${ }^{18} \mathrm{~F}-\mathrm{FDG}$ PET/CT in the management of squamous cell carcinoma of the head and neck and thyroid carcinoma. J Nucl Med. 2007;48(suppl 1):58S-67S.

87. Robbins KT, Shannon K, Vieira F. Superselective neck dissection after chemoradiation: feasibility based on clinical and pathologic comparisons. Arch Otolaryngol Head Neck Surg. 2007;133:486-489.

88. Weber WA, Wieder H. Monitoring chemotherapy and radiotherapy of solid tumors. Eur J Nucl Med Mol Imaging. 2006;33(suppl 1):27-37.

89. Schoder H, Moskowitz C. PET imaging for response assessment in lymphoma: potential and limitations. Radiol Clin North Am. 2008;46:225-241.

90. Brun E, Kjellen E, Tennvall J, et al. FDG PET studies during treatment: prediction of therapy outcome in head and neck squamous cell carcinoma. Head Neck. 2002;24:127-135.

91. ClinicalTrials.gov. Docetaxel based chemotherapy plus or minus induction chemotherapy to decrease events in head and neck cancer (DeCIDE). ClinicalTrials.gov identifier NCT00117572. Available at: http://clinicaltrials. gov/ct2/show/NCT00117572?term=DECIDE\&rank=4. Accessed March 27, 2009.

92. ClinicalTrials.gov. TPF induction with concomitant chemoradiation to treat patients with head and neck cancer (Condor). ClinicalTrials.gov identifier NCT00774319. Available at: http://clinicaltrials.gov/ct2/show/NCT00774319? term $=$ head + and + neck + cancer $\&$ recr $=$ Open\&rank $=42$. Accessed March 27, 2009.

93. ClinicalTrials.gov. Induction chemotherapy prior to radio-immunotherapy in head and neck cancer stage III/IV: a methodical trial (ASOG-HNO1). ClinicalTrials.gov identifier NCT00502463. Available at: http://clinicaltrials. gov/ct2/show/NCT00502463. Accessed March 27, 2009.

94. Shintani SA, Foote RL, Lowe VJ, Brown PD, Garces YI, Kasperbauer JL. Utility of PET/CT imaging performed early after surgical resection in the adjuvant treatment planning for head and neck cancer. Int J Radiat Oncol Biol Phys. 2008;70:322-329.

95. Heron DE, Andrade RS, Beriwal S, Smith RP. PET-CT in radiation oncology: the impact on diagnosis, treatment planning, and assessment of treatment response. Am J Clin Oncol. 2008;31:352-362.

96. Shields AF. PET imaging with ${ }^{18} \mathrm{~F}$-FLT and thymidine analogs: promise and pitfalls. J Nucl Med. 2003;44:1432-1434.

97. Rasey JS, Grierson JR, Wiens LW, Kolb PD, Schwartz JL. Validation of FLT uptake as a measure of thymidine kinase-1 activity in A549 carcinoma cells. $J$ Nucl Med. 2002;43:1210-1217.

98. Schwartz JL, Tamura Y, Jordan R, Grierson JR, Krohn KA. Effect of p53 activation on cell growth, thymidine kinase-1 activity, and $3^{\prime}$-deoxy3'fluorothymidine uptake. Nucl Med Biol. 2004;31:419-423.

99. Herrmann K, Wieder HA, Buck AK, et al. Early response assessment using $3^{\prime}$ deoxy- $3^{\prime}-\left[{ }^{18} \mathrm{~F}\right]$ fluorothymidine-positron emission tomography in high-grade non-Hodgkin's lymphoma. Clin Cancer Res. 2007;13:3552-3558.

100. Molthoff $\mathrm{CF}$, Klabbers BM, Berkhof J, et al. Monitoring response to radiotherapy in human squamous cell cancer bearing nude mice: comparison of $2^{\prime}$-deoxy-2'-[ ${ }^{18}$ F $]$ fluoro-D-glucose (FDG) and $3^{\prime}-\left[{ }^{18}\right.$ F $]$ fluoro- $3^{\prime}$-deoxythy midine (FLT). Mol Imaging Biol. 2007;9:340-347.

101. Atkinson DM, Clarke MJ, Mladek AC, et al. Using fluorodeoxythymidine to monitor anti-EGFR inhibitor therapy in squamous cell carcinoma xenografts. Head Neck. 2008;30:790-799.

102. Troost EG, Vogel WV, Merkx MA, et al. ${ }^{18}$ F-FLT PET does not discriminate between reactive and metastatic lymph nodes in primary head and neck cancer patients. J Nucl Med. 2007;48:726-735.

103. Brizel DM, Sibley GS, Prosnitz LR, Scher RL, Dewhirst MW. Tumor hypoxia adversely affects the prognosis of carcinoma of the head and neck. Int J Radiat Oncol Biol Phys. 1997;38:285-289. 
104. Becker A, Hansgen G, Bloching M, Weigel C, Lautenschlager C, Dunst J. Oxygenation of squamous cell carcinoma of the head and neck: comparison of primary tumors, neck node metastases, and normal tissue. Int J Radiat Oncol Biol Phys. 1998;42:35-41.

105. Nordsmark M, Bentzen SM, Rudat V, et al. Prognostic value of tumor oxygenation in 397 head and neck tumors after primary radiation therapy: an international multi-center study. Radiother Oncol. 2005;77:18-24.

106. Barendsen GW, Koot CJ, Van Kersen GR, Bewley DK, Field SB, Parnell CJ. The effect of oxygen on impairment of the proliferative capacity of human cells in culture by ionizing radiations of different LET. Int J Radiat Biol Relat Stud Phys Chem Med. 1966;10:317-327.

107. Hockel M, Schlenger K, Mitze M, Schaffer U, Vaupel P. Hypoxia and radiation response in human tumors. Semin Radiat Oncol. 1996;6:3-9.

108. Gabalski EC, Adam M, Pinto H, Brown JM, Bloch DA, Terris DJ. Pretreatment and midtreatment measurement of oxygen tension levels in head and neck cancers. Laryngoscope. 1998;108:1856-1860.

109. Tatum JL, Kelloff GJ, Gillies RJ, et al. Hypoxia: importance in tumor biology, noninvasive measurement by imaging, and value of its measurement in the management of cancer therapy. Int J Radiat Biol. 2006;82:699-757.

110. Schoder H, Ong SC. Fundamentals of molecular imaging: rationale and applications with relevance for radiation oncology. Semin Nucl Med. 2008;38:119-128.

111. Rosenberg A, Knox S. Radiation sensitization with redox modulators: a promising approach. Int J Radiat Oncol Biol Phys. 2006;64:343-354.

112. Kaanders JH, Pop LA, Marres HA, et al. ARCON: experience in 215 patients with advanced head-and-neck cancer. Int $J$ Radiat Oncol Biol Phys. 2002;52:769-778.

113. Rischin D, Peters L, O'Sullivan B, et al. Phase III study of tirapazamine, cisplatin and radiation versus cisplatin and radiation for advanced squamous cell carcinoma of the head and neck [abstract]. J Clin Oncol. 2008;26:(suppl):LBA6008.

114. Rischin D, Hicks RJ, Fisher R, et al. Prognostic significance of $\left[{ }^{18} \mathrm{~F}\right]-$ misonidazole positron emission tomography-detected tumor hypoxia in patients with advanced head and neck cancer randomly assigned to chemoradiation with or without tirapazamine: a substudy of Trans-Tasman Radiation Oncology Group Study 98.02. J Clin Oncol. 2006;24:2098-2104.

115. Lee N, Nehmeh S, Schöder H, et al. Prospective trial of incorporating pre-/ mid-treatment $\left[{ }^{18} \mathrm{~F}\right]$-misonidazole positron emission tomography for head-andneck cancer patients undergoing concurrent chemoradiotherapy. Int J Radiat Oncol Biol Phys. February 7, 2009 [Epub ahead of print].

116. Agulnik M, da Cunha Santos G, Hedley D, et al. Predictive and pharmacodynamic biomarker studies in tumor and skin tissue samples of patients with recurrent or metastatic squamous cell carcinoma of the head and neck treated with erlotinib. J Clin Oncol. 2007;25:2184-2190.

117. Inoue A, Suzuki T, Fukuhara T, et al. Prospective phase II study of gefitinib for chemotherapy-naive patients with advanced non-small-cell lung cancer with epidermal growth factor receptor gene mutations. J Clin Oncol. 2006;24:3340-3346.

118. Bastholt L, Specht L, Jensen K, et al. Phase I/II clinical and pharmacokinetic study evaluating a fully human monoclonal antibody against EGFr (HuMaxEGFr) in patients with advanced squamous cell carcinoma of the head and neck. Radiother Oncol. 2007;85:24-28.

119. Su H, Bodenstein C, Dumont RA, et al. Monitoring tumor glucose utilization by positron emission tomography for the prediction of treatment response to epidermal growth factor receptor kinase inhibitors. Clin Cancer Res. 2006;12:5659-5667.

120. Cai W, Chen K, He L, Cao Q, Koong A, Chen X. Quantitative PET of EGFR expression in xenograft-bearing mice using ${ }^{64} \mathrm{Cu}$-labeled cetuximab, a chimeric
anti-EGFR monoclonal antibody. Eur J Nucl Med Mol Imaging. 2007;34:850858.

121. Mishani E, Abourbeh G, Jacobson O, et al. High-affinity epidermal growth factor receptor (EGFR) irreversible inhibitors with diminished chemical reactivities as positron emission tomography (PET)-imaging agent candidates of EGFR overexpressing tumors. J Med Chem. 2005;48:5337-5348.

122. Pal A, Glekas A, Doubrovin M, et al. Molecular imaging of EGFR kinase activity in tumors with ${ }^{124}$ I-labeled small molecular tracer and positron emission tomography. Mol Imaging Biol. 2006;8:262-277.

123. Kerbel RS. Tumor angiogenesis. N Engl J Med. 2008;358:2039-2049.

124. Haubner R, Weber WA, Beer AJ, et al. Noninvasive visualization of the activated alphavbeta3 integrin in cancer patients by positron emission tomography and $\left[{ }^{18} \mathrm{~F}\right]$ galacto-RGD. PLoS Med. 2005;2:e70.

125. Beer AJ, Haubner R, Goebel M, et al. Biodistribution and pharmacokinetics of the $\alpha_{\mathrm{v}} \beta_{3}$-selective tracer ${ }^{18} \mathrm{~F}$-galacto-RGD in cancer patients. $\mathrm{J} \mathrm{Nucl} \mathrm{Med}$. 2005;46:1333-1341.

126. Clezardin P. Recent insights into the role of integrins in cancer metastasis. Cell Mol Life Sci. 1998;54:541-548.

127. Beer AJ, Grosu AL, Carlsen J, et al. $\left[{ }^{18} \mathrm{~F}\right]$ galacto-RGD positron emission tomography for imaging of alphavbeta3 expression on the neovasculature in patients with squamous cell carcinoma of the head and neck. Clin Cancer Res. 2007;13:6610-6616.

128. Nemunaitis J, O'Brien J. Head and neck cancer: gene therapy approaches. Part 1: adenoviral vectors. Expert Opin Biol Ther. 2002;2:177-185.

129. Nemunaitis J, Ganly I, Khuri F, et al. Selective replication and oncolysis in p53 mutant tumors with ONYX-015, an E1B-55kD gene-deleted adenovirus, in patients with advanced head and neck cancer: a phase II trial. Cancer Res. 2000;60:6359-6366.

130. Wong RJ, Joe JK, Kim SH, Shah JP, Horsburgh B, Fong Y. Oncolytic herpesvirus effectively treats murine squamous cell carcinoma and spreads by natural lymphatics to treat sites of lymphatic metastases. Hum Gene Ther. 2002;13:1213-1223.

131. Gil Z, Kelly KJ, Brader P, Shah JP, Fong Y, Wong RJ. Utility of a herpes oncolytic virus for the detection of neural invasion by cancer. Neoplasia. 2008; 10:347-353.

132. McCollum AD, Burrell SC, Haddad RI, et al. Positron emission tomography with ${ }^{18} \mathrm{~F}$-fluorodeoxyglucose to predict pathologic response after induction chemotherapy and definitive chemoradiotherapy in head and neck cancer. Head Neck. 2004;26:890-896.

133. Ware RE, Matthews JP, Hicks RJ, et al. Usefulness of fluorine-18 fluorodeoxyglucose positron emission tomography in patients with a residual structural abnormality after definitive treatment for squamous cell carcinoma of the head and neck. Head Neck. 2004;26:1008-1017.

134. Brkovich VS, Miller FR, Karnad AB, Hussey DH, McGuff HS, Otto RA. The role of positron emission tomography scans in the management of the $\mathrm{N}$-positive neck in head and neck squamous cell carcinoma after chemoradiotherapy. Laryngoscope. 2006;116:855-858.

135. Tan A, Adelstein DJ, Rybicki LA, et al. Ability of positron emission tomography to detect residual neck node disease in patients with head and neck squamous cell carcinoma after definitive chemoradiotherapy. Arch Otolaryngol Head Neck Surg. 2007;133:435-440.

136. Yao M, Smith R, Hoffman H, et al. Clinical significance of postradiotherapy $\left.{ }^{[18} \mathrm{F}\right]$-fluorodeoxyglucose positron emission tomography imaging in management of head and neck cancer: a long term outcome report. Int J Radiat Oncol Biol Phys. In press. 